\title{
DIREITO E LITERATURA NO BRASIL
}

\section{Eduardo Aleixo Monteiro ${ }^{1}$}

\section{Resumo}

Aos poucos, vem-se abandonando as concepções que apreciam o Direito isoladamente, sem o relacionar a outras disciplinas. Este artigo pretende definir os estudos fomentados pelo Movimento Direito e Literatura, a fim de traçar um panorama histórico que estime a sua repercussão no Brasil.

Palavras-chave: Direito; Arte; Literatura; Interdisciplinaridade; Brasil.

\section{LAW AND LITERATURE IN BRAZIL}

\begin{abstract}
Little by little, it has been abandoning the conceptions that appreciate Law isolatedly, without relating it to other disciplines. This article intends to define the studies fomented by the Law and Literature Movement, in order to draw an historical panorama that esteems its repercussion in Brazil.
\end{abstract}

Keywords: Law; Art; Literature; Interdisciplinarity; Brazil.

\section{Introdução}

Este trabalho ${ }^{2}$ pretende definir os estudos fomentados pelo Movimento Direito e Literatura, a fim de traçar um panorama histórico que estime a sua repercussão no Brasil. Para tanto, serão esboçadas as propostas mais aceitas de metodologia e classificação desses estudos.

É consabido que juristas e literatos sempre seguiram carreiras paralelas. Walter Scott, Balzac, Flaubert, Tolstói e - por que não dizer? - John Grisham atestam isso. A literatura brasileira também se encontra repleta de exemplos, como Gregório de Matos Guerra, Cláudio Manoel da Costa, Tomás Antônio Gonzaga, Gonçalves Dias, José de Alencar, Raimundo Correia, Alphonsus de Guimarães e Graça Aranha.

\footnotetext{
${ }^{1}$ Bacharel em Direito pela Universidade Federal de Pernambuco, mestre em Filosofia e Teoria Geral do Direito pela Universidade de São Paulo, mestrando em Teatro, Dança e Performance na Universidade Estadual de Campinas e membro da Rede Brasileira Direito e Literatura. E-mail: eduardoaleixomonteiro@ hotmail.com.

${ }^{2}$ A pesquisa foi concluída em 2016, por ocasião de um mestrado em Filosofia e Teoria Geral do Direito na Universidade de São Paulo. Em 2017, André Karam Trindade e Luísa Giuliani Bernsts chegaram a resultados semelhantes no artigo $O$ estudo do direito e literatura no Brasil: surgimento, evolução e expansão.
} 
Muito embora desde o século XVIII lecione-se Shakespeare nas faculdades inglesas de direito e a despeito de vários estudiosos haverem percebido as conexões entre as disciplinas como Jhering, Jellinek, Radbruch e o próprio Kelsen -, foi o Law and Literature Movement que impulsionou a área. Iniciado nos Estados Unidos em 1970, com a afamada The Legal Imagination $^{\mathbf{3}}$ de James Boyd White, o movimento tornou-se um empreendimento nos anos 1980, quando já existiam revistas especializadas, associações o investigando e até uma cadeira ligada a ele nas faculdades norte-americanas. De imediato, as suas influências chegaram à Europa e, na última década, ao Brasil.

No Brasil, os estudos jurídico-literários antecederam o movimento americano e nem todos os trabalhos sobre Direito e Literatura publicados após a década de 1970 tiveram influência estadunidense. O movimento brasileiro está em vias de se tornar empreendimento. As publicações, os grupos de pesquisa, os eventos, os cursos e, sobretudo, a associação e a revista especializada permitem afirmá-lo.

\section{Inter, trans, multi ou pluridisciplinaridade na pesquisa jurídica}

Em uma visão perfunctória da evolução da cultura no Ocidente, pode-se denominar a primeira fase das relações entre direito natural e direito positivo como fase de indiferenciação. Nela não havia a consciência de uma separação entre o direito que efetivamente acontece na comunidade e o direito criado pela natureza, pela física, pela divindade. Para que haja essa consciência, é necessário já um alto grau de sofisticação, de complexificação social (ADEODATO, 2006). Existia, portanto, em determinadas comunidades, uma espécie de indiferenciação entre o que hoje se entende por direito, moral, religião, arte etc.

Hoje em dia, o isolamento em que se encontra parte da ciência jurídica é devido, em boa medida, justamente ao processo de diferenciação pelo qual passou o direito. De acordo com Luis Alberto Warat, durante o processo, perdeu-se ou se profanou algo sagrado, o sagrado do direito, que poderia ser restabelecido mediante uma aproximação com a arte (2004). Maria Francisca Carneiro, para quem o conceito de Justiça no Direito corresponde ao de Belo na Arte, compartilha da opinião.

A característica do conhecimento estético, para vários autores, é que ele advém da sensibilidade. Um quadro de Van Gogh ou Monet contém elementos sensíveis e

\footnotetext{
${ }^{3}$ Neste trabalho, quando se trata de obras não traduzidas para o português, foram conservados os seus títulos originais.
} 
emocionais que não se encontram em um composto químico ou em uma equação matemática. Assim, indagamos se, ao conhecer o Direito e ao experienciá-lo, podese ter também uma experiência estética, impregnada de sensibilidade na apreciação do justo com o belo. Nesse caso, o Direito não seria uma atividade meramente racional, mas englobaria também aspectos tangentes à emoção e à sensibilidade (CARNEIRO, 2008, p.14).

Aos poucos, vem-se abandonando as concepções que apreciam o Direito isoladamente, sem o relacionar a outras disciplinas. Em resposta a uma visão positivista do fenômeno jurídico, multiplicam-se trabalhos que o vinculam a outros campos epistêmicos. Eliane Botelho Junqueira registrou essa tendência.

Diferentes análises sobre o direito vêm disputando espaço na academia norteamericana a partir da década de sessenta, quando se inicia o movimento direito e sociedade e, logo em seguida, o movimento direito e desenvolvimento. As correntes law and economics, law and society, critical legal studies, critical race theory $\mathrm{e}$ feminist jurisprudence, dentre outras, sem dúvida são conhecidos exemplos dessa efervescente produção acadêmica. Mais recentemente, o "movimento" law and literature conquistou importante espaço institucional, quer através da publicação de revistas especializadas, quer através da criação de disciplinas específicas dentro dos currículos das faculdades de direito (JUNQUEIRA, 1998, p.21).

Tercio Sampaio Ferraz Junior assume como premissas que na estraneidade o sentido se mostra (2009) e que a arte torna estranho aquilo que é evidente (2014). Partindo de Walter Benjamin, afirma que as pessoas ou se recolhem, ou se divertem perante uma obra de arte. As pessoas ou seriam consumidas pelas obras que exigem recolhimento (arte-recolhimento), ou consumiriam as obras que proporcionam diversão (arte-diversão). Com a diminuição do recolhimento, o espírito crítico e o gozo se confundem, quer dizer, criticar e gostar se confundem. Na terminologia do autor, as noções de arte-recolhimento e arte-diversão correspondem às noções de direito-interiorização e direito-espetáculo. Enquanto a arterecolhimento torna estranho aquilo que é evidente, a arte-diversão torna evidente aquilo que é estranho. Analogamente, enquanto o direito-interiorização torna estranho aquilo que é evidente, o direito-espetáculo torna evidente aquilo que é estranho.

O conceito de interdisciplinaridade foi trabalhado e retrabalhado com êxito por dois teóricos brasileiros. No campo pedagógico, sobressai Ivani Fazenda. No epistemológico, que mais interessa aqui, Hilton Japiassu (1976). Este diferenciou inter, trans, multi e pluridisciplinaridade, mediante a intensidade das trocas entre os especialistas e o grau de integração real das disciplinas. Admitindo "disciplina" como "ciência", multidisciplinaridade seria a justaposição de disciplinas, o estudo de um objeto sob diferentes ângulos, sem a necessidade de cooperação entre os especialistas e com pouca ou nenhuma integração entre as disciplinas. Na pluridisciplinaridade, há justaposição com cooperação, mas a integração tampouco é satisfatória. Já a interdisciplinaridade pressupõe cooperação e integração 
suficientes para que exista reciprocidade nos intercâmbios e cada disciplina saia enriquecida do processo interativo. A transdisciplinaridade vai além, na medida em que ignora os limites entre as disciplinas.

Um artigo jurídico que se vale da Literatura somente como ilustração está entre a multi e a pluridisciplinaridade, a depender da cooperação. Esse tipo de artigo propõe soluções apenas jurídicas. A literatura é colonizada, judicializada, instrumentalizada, servindo somente de epígrafe. Conforme François Ost, trata-se de uma "diversão erudita" (2005, p.25). No mesmo sentido, Judith Martins-Costa.

Para que a expressão "Direito e Literatura" não etiquete mais uma das incontáveis e
descartáveis modas que infestam o consumismo universitário ou enfeitam as
trivialidades das colunas sociais, é preciso saber que obras literárias não são
avalistas de clichês, não se prestam a exemplificar conceitos para uso prático ou para
citação falsamente erudita. São instrumentos óticos, a propiciar, pelo afinamento da
percepção, a apreensão de estratégias retóricas, das dobras que escondem a
multiplicidade de discursos que uma mesma palavra suscita (MARTINS-COSTA,
2013, p.XII).

Já um artigo cujos elementos interessem, por exemplo, tanto à Sociologia Jurídica quanto à Historiografia Literária está entre a inter e a transdisciplinaridade, a depender da integração.

Diversos entusiastas do movimento norte-americano examinam o Direito e a Literatura sob um enfoque transdisciplinar. Logo, não falam em sistemas fechados, mas em temas transversais, que se relacionam entre si e para com o todo, integrando os saberes ao invés de fragmentá-los. Não é outro o entendimento de Clarice Beatriz da Costa Söhngen.

Assumir uma postura transdisciplinar a partir da análise do discurso dos textos literários com a finalidade de enfrentar temáticas jurídicas tem-nos convocado a romper as zonas limítrofes das fronteiras e muros que ainda permanecem erguidos para salvaguardar a autonomia dos diferentes saberes da ciência (SÖHNGEN, 2008, p.13).

Maria Francisca Carneiro, entretanto, observa que "há críticas à transdisciplinaridade, como, por exemplo, a de gerar conhecimentos superficiais, pois, ao se aprofundar, o pesquisador se especializa e, assim, volta às disciplinas tradicionais" (2009, p.179). Outra crítica comum repousa na vaguidade e na imprecisão das conclusões. Daí a interdisciplinaridade ser possivelmente a melhor opção metodológica para a pesquisa em Direito e Literatura.

[...] a interdisciplinaridade é um imperativo metodológico necessário para a superação das enormes lacunas de conhecimento geradas nos diversos saberes, em virtude da prevalência de concepções formalistas e positivistas, especialmente no âmbito das áreas de conhecimento que ocupam o pretenso cume dos saberes sérios e solenes, como é o caso do Direito (SELIGMANN-SILVA, 2012, p.12). 
A pesquisa interdisciplinar, ao promover um diálogo horizontal entre as disciplinas, parece mais tangível, porque menos complexa que a transdisciplinar. Contudo, os estudos do Direito a partir da Literatura jamais importarão tarefa fácil. Richard Posner aconselha que os profissionais de ambas as áreas não escrevam a respeito de assuntos que desconheçam, sob pena de, em primeiro lugar, incorrerem no amadorismo, "a praga da interdisciplinaridade"; e, em segundo lugar, cometerem pecado ainda maior, atraindo outros colegas a também escreverem sobre assuntos que desconhecem, "a atratividade da interdisciplinaridade" (2009, p.6-7).

O jurista que desembarca em terra literária assemelha-se a Colombo pondo os pés no novo mundo - ignorante da natureza exata de sua descoberta: ilha ou continente? Índia ou América? Muitas outras surpresas ainda o esperam, e ele certamente será obrigado a modificar mais de uma vez o traçado dos mapas que traçou presuntivamente. Pensava ele partir em busca dos fundamentos do direito? Se os encontrou seguramente do lado da lei, do juiz e da consciência, não faltaram abismos abrindo-se a seus pés e recolocando a questão do lado do crime, da impostura, da violência e de uma lei muito arcaica de necessidade. Pensava descobrir o segredo das leis em seu conteúdo? Ei-lo remetido de volta a suas condições de recepção: a liberdade no deserto (Êxodo), o aidos (respeito) na cidade (Protágoras). Acreditava celebrar o triunfo da justiça sobre a vingança? Ele percebeu que a questão passa pelos desvios da linguagem e a emergência da autonomia pessoal (OST, 2005, p.58).

Também Bruno Meyerhof Salama demonstra claramente as mesmas preocupações ao comentar sobre a introdução da disciplina Direito e Economia nos cursos brasileiros de graduação ou pós-graduação.

Há pelo menos dois problemas centrais em qualquer tentativa de introdução de
matéria interdisciplinar na academia. O primeiro é o de que os movimentos
interdisciplinares podem ser tomados por uma certa ideia de grandeza, um torpor
que surge da ilusão de terem as respostas definitivas para uma enorme gama de
problemas. No afã de conquistarem seu espaço na academia - e na política - tais
movimentos superestimam suas potenciais contribuições e subestimam seus limites.
O segundo problema é que a interdisciplinaridade é complexa, e seu estudo requer
um grau de profundidade que nem sempre se pode atingir nas salas de aula. As
tentativas de introdução do estudo interdisciplinar - de qualquer estudo
interdisciplinar - nos cursos de Direito são frequentemente feitas sem o nível de
sofisticação (ou de cuidado) necessário, e assim corre-se o risco de lecionar versões
excessivamente limitadas (ou mesmo grotescas, do tipo "receita de bolo"),
obscurecendo a real utilidade do estudo. Reitere-se: esses dois problemas são, a meu
ver, comuns a toda tentativa interdisciplinar; não apenas ao Direito e Economia. É
por isso que a interdisciplinaridade às vezes anda próxima do charlatanismo
intelectual (SALAMA, 2008, p.60).

Com efeito, os principais nomes do movimento americano possuem formação acadêmica nas duas matérias. Vale lembrar que para cursar Direito nos Estados Unidos é preciso possuir diploma de graduação com no mínimo quatro anos em qualquer área. Some-se a isso o fato de a common law ser mais aberta, ou menos fechada, a propostas antipositivistas do que a civil law e se entenderá por quais razões o movimento não teve a mesma 
receptividade no Brasil. Ora, se, no Brasil, Direito e Literatura é apenas linha de pesquisa, nos Estados Unidos, já se tornou área de concentração.

Não se infira daí qualquer ressalva à autodidaxia. É mister superar a antinomia entre especialização e interdisciplinaridade. $O$ jurista não precisa necessariamente de uma graduação em Letras para contribuir com o Movimento Direito e Literatura. O próprio Richard Posner tornou-se o maior expoente do Law and Economics sem nunca haver cursado Economia. No que toca à civil law do Brasil, não deve ser encarada como um obstáculo intransponível ao enraizamento da pesquisa jurídico-literária no país. Hoje todo sistema legal tende para a interdisciplinaridade. Além do mais, o movimento estadunidense não deve ser recepcionado de joelhos. Embora permaneça a maneira mais organizada de estudar o Direito a partir da Arte, o Law and Literature possui contradições e, há quem diga, talvez signifique apenas uma reposta ao Law and Economics. Kenji Yoshino escreveu sobre o assunto.

Três décadas após James Boyd White inaugurá-lo com sua The Legal Imagination, o empreendimento direito e literatura apresenta sintomas contraditórios. Por um lado, o campo parece estar florescendo como nunca. Recentemente, viu-se uma inundação de livros aproximando direito e literatura. $\mathrm{O}$ empreendimento penetrou nas academias jurídicas. Conferências sobre o assunto ocorrem com alguma frequência e atraem juristas, estudiosos de Direito e de Literatura. Por outro lado, o campo continua a ser infestado pelo ceticismo. Embora o Law and Literature seja contemporâneo do Law and Economics, e provavelmente uma resposta a ele, os estudos em Law and Literature ficam muito atrás dos em Law and Economics, pelo menos quantitativamente. O livro mais adotado nos cursos de direito e literatura é o de Richard Posner, conhecido pelas suas aproximações entre direito e economia. Esse livro afirma que direito e literatura têm menos a dizer um ao outro do que se pensa e observa que cursos no campo ainda são considerados "macios" (YOSHINO, 2005, p.1836-1837).

O binômio Direito e Literatura conta com alguns manuais. No entanto, Richard Posner foi o único protagonista do movimento americano que se aventurou a escrever um. A primeira edição da obra que Posner dedicou ao Law and Literature lhe serviu mais para defender o Law and Economics, a principal corrente da filosofia do direito norte-americana. Esse caráter defensivo desapareceu já na segunda edição, enquanto a terceira consolidou o protagonismo do scholar. Com efeito, Posner deixou de ser um crítico do movimento norte-americano e hoje o protagoniza ao lado de James Boyd White e Richard Weisberg (MONTEIRO, 2012).

É importante assinalar que o interesse gerado pelo movimento americano entre advogados e acadêmicos do Direito não foi correspondido com interesse similar dos escritores e acadêmicos da Literatura (PÉREZ, 2006). Nada obstante, o conceito de Law and Literature envolve tanto o estudo do Direito a partir da Literatura quanto o estudo da Literatura a partir do Direito. Seja qual for o percurso adotado, só haverá interdisciplinaridade, vale retomar 
Japiassu, quando houver cooperação e integração suficientes para que exista reciprocidade nos intercâmbios e cada disciplina saia enriquecida do processo interativo.

\section{A classificação dos estudos jurídico-literários}

Segundo James Boyd White, jamais existiu um manifesto que radicasse a metodologia dos estudos jurídico-literários (2000). Resta, dessarte, apontar as linhas de pesquisa dominantes.

A melhor maneira de se definirem os estudos em Direito e Literatura é mediante sua classificação. Thomas Morawetz chegou a dividi-los em até sete campos (1996). Andrés Botero, em seis (2008). Philippe Malaurie propôs quatro campos somente (1997). Guyora Binder e Robert Weisberg defenderam classificação mais simples e, talvez por isso, popular (2000). Para eles, haveria apenas o direito na literatura, law in literature, e o direito como literatura, law as literature. Normalmente, acrescenta-se à fórmula de Binder e Weisberg um terceiro campo, o direito da literatura, law of literature, obtendo-se a classificação tripartida que será utilizada neste trabalho. Apesar de certos autores adotarem divisão metodológica própria, a tricotomia é praticamente consensual e impressiona pela funcionalidade, tanto assim que, com algum esforço, os sete campos de Morawetz, os seis de Botero e os quatro de Malaurie podem ser reduzidos a ela.

\subsection{O direito na literatura}

O direito na literatura é a relação mais óbvia. José Calvo González enxerga nesse campo a interseção instrumental entre as disciplinas, porquanto cada uma serviria de instrumento para a compreensão da outra (2008). O direito na literatura tem a ver com a abordagem literária do fenômeno jurídico, com o que pensa a Literatura a propósito do Direito. Reside, pois, na análise de obras ficcionais que versem sobre matéria judicial. O sistema jurídico é retratado como um microcosmo da sociedade, por meio de temas que interessam tanto a juristas quanto a leigos.

Acredita-se que a leitura dessas obras assiste à compreensão do Direito, porque suscita questões difíceis de alcançar em âmbito exclusivamente jurídico. Segundo Judith MartinsCosta, a Literatura funciona como o espelho de Perseu, um espelho invertido capaz de revelar 
significados normativos que os textos não revelam por si sós (2011). Decorrem daí as alusões ao potencial pedagógico da Literatura para os juristas, que, inclusive, têm a sua capacidade de expressão aprimorada através das leituras.

Consoante o Law and Literature as Ethical Discourse, resgata-se determinado humanismo, na medida em que valores éticos e culturais são trazidos à baila. Para Martha Nussbaum, "a imaginação literária é ingrediente essencial de postura ética que pede para nós nos preocuparmos com o bem de pessoas cujas vidas estão distantes das nossas" (NUSSBAUM, 1995, p.XVI). Katya Kozicki leciona no mesmo sentido.

A premissa assumida por todos é que o saber jurídico não pode restar isolado dos demais saberes e que a reflexão sobre o direito e sobre o próprio conhecimento do direito necessitam de uma análise mais ampla e abrangente [...] A literatura permite a colocação de questões que muitas vezes são reprimidas no âmbito das escolas de direito (como também na filosofia) e nos aproxima da questão do sujeito por caminhos outros que não apenas o conceito formal do sujeito de direito (KOZICKI, 2006, p.6-7).

$\mathrm{O}$ direito na literatura ainda proporciona uma consciência empática - a empatia de colocar-se no lugar do outro -, que nunca se adquiriria mediante trabalhos de História, Ciências Sociais ou Jornalismo. É que a empatia entre leitor e personagem não aconteceria através desses trabalhos como acontece por meio da Literatura (POSNER, 2009). Nesse sentido, Rafael Tomaz de Oliveira, para quem o livro que melhor explica o século XX não é um livro de História, Sociologia, Filosofia ou Antropologia, é um livro de Literatura: O homem sem qualidades, escrito por Robert Musil (informação verbal) ${ }^{4}$.

Costuma-se indicar John Henry Wigmore como precursor ou pai fundador do law in literature, uma vez que publicou, no ano de 1908, A list of one hundred legal novels, elencando, em categorias temáticas, as obras literárias que entendia passíveis de análise judicial. O legal novel não existia enquanto gênero antes de Wigmore (WEISBERG, 2006). Em 1976, Richard Weisberg reformulou parcialmente a lista de Wigmore, acrescentando novas obras e categorias. Foi também Richard Weisberg quem conceituou uma manifestação bastante comum do direito na literatura, o romance de procedimento. O procedural novel é um romance passível de análise jurídica no qual "uma estrutura é criada que endossa a compreensão verificável de eventos anteriores ao mesmo tempo em que se questiona a meramente subjetiva, ou altamente articulada, interpretação desses eventos" (WEISBERG, 1988, p.226).

\footnotetext{
${ }^{4}$ I Simpósio de Direito e Literatura, Florianópolis, 2010.
} 
Percebem-se algumas recorrências na escolha das obras a analisar, quais sejam, a Antígona de Sófocles, a Oréstia de Ésquilo, Medida por Medida ou O Mercador de Veneza de Shakespeare, O Estrangeiro de Camus, As Viagens de Gulliver de Swift, Crime e Castigo ou Os Irmãos Karamazov de Dostoievski, 1984 de Orwell, Admirável Mundo Novo de Huxley, O Senhor das Moscas de Golding, O Homem sem Qualidades de Musil, Os Miseráveis de Victor Hugo, Germinal de Zola, Oliver Twist de Dickens, Billy Budd de Melville, a Bíblia, entre outras.

Sobre o direito na literatura, cumpre fazer duas últimas observações. A primeira: os estudos em Direito e Psicanálise não raro desembocam no law in literature, vez que a Psicanálise sempre esteve intimamente ligada à Literatura. A segunda: Teatro, Cinema e Música, se reduzidos a termo, quer dizer, se considerados tão-somente enquanto texto, podem, e devem, ser juridicamente analisados enquanto obras literárias. Afinal, como apontou Fernando Pessoa mediante Álvaro de Campos, "toda arte é uma forma de literatura, porque toda arte é dizer qualquer coisa" (1980, p.279).

\subsection{O direito como literatura}

O direito como literatura, vertente mais sofisticada que a anterior, resulta na interseção estrutural de José Calvo Gonzáles, segundo a qual ambas as disciplinas lidam com relações humanas mediante textos (2008). O campo é eventualmente chamado de literatura no direito, literature in law, porque encerra uma análise literária do texto jurídico, ao contrário do law in literature, uma análise jurídica do texto literário. Assim sendo, o law as literature equipara o Direito à Literatura sob as perspectivas retórica, narrativa e interpretativa, oriundas, respectivamente, do Law and Literature as Language, do Legal Storytelling Movement e do Legal Texts as Literary Texts (TRINDADE; GUBERT, 2008).

Pela primeira perspectiva, tanto o Direito quanto a Literatura usariam a linguagem persuasivamente para afirmar os valores da sociedade, consistindo, por óbvio, em disciplinas retóricas. Daí Benjamin Nathan Cardozo, founding father como Wigmore, publicar, em 1925, um ensaio identificando seis tipos de discurso jurídico a partir do estilo e se referindo ao Direito enquanto Literatura stricto sensu. James Boyd White, no mesmo tom, observa que o texto, para ser considerado literário, não precisa pertencer à alta literatura, mas a qualquer 
gênero ou proveniência, inclusive ao Direito, desde que exiba certo tipo de imaginação e certo senso de linguagem (2000).

Richard Posner concorda com as assertivas. Também ele apreciou elementos estilísticos e retóricos no discurso jurídico, afirmando não haver absolutamente nada de extravagante nisso, porquanto muito do que é Literatura hoje já foi Religião ou Política um dia (POSNER, 2009). Nesse influxo, o que é Direito hoje pode, com efeito, ser Literatura um dia. Pierre Leval, a propósito, acredita que esse dia já chegou (1996). Posner suspeita que as reservas de muitos advogados sobre Cardozo devem-se à relutância em aceitar que algo não-profissional, unprofessional, como a habilidade literária, faça grande um juiz, pois os advogados "podem admitir que o Direito às vezes seja Poesia, mas dificilmente admitirão que a Poesia às vezes seja Direito" (1990, p.134).

Pela segunda perspectiva, o fenômeno jurídico seria um conjunto de relatos - tal qual o é a Literatura - só que narrados perante o tribunal. Haveria uma narrativa processual, não um encadeamento de atos processuais, como ensina a Teoria Geral do Processo. Nessa senda, Ronald Dworkin comparou o Direito, common law, a um romance em cadeia, chain novel (2000), no que foi parafraseado por Ferreira da Cunha.

O processo penal é uma peça literária a várias mãos. Vai-se desenrolando em vários capítulos, cada um narrado por um diferente interveniente, com potestas e auctoritas diferentes, mas sempre um coautor. A sentença é o capítulo final do livro. Possíveis recursos e revisões de sentença são novas aventuras, ou posfácios, novos volumes. Nalguns, como nas obras rocambolescas de Ponson Du Terrail, os mortos ressuscitam, ou as honras são reabilitadas (FERREIRA DA CUNHA, 2008a, p.79).

Conforme o mesmo autor, "desde Ronald Dworkin que se sabe como um processo judicial é afinal uma narrativa, feita de várias narrativas adversas, e que a sentença é a conclusão, o capítulo-epílogo (ainda que a estória consinta continuações... ou recursos)" (FERREIRA DA CUNHA, 2008b, p.9). Germano Schwartz, em consonância com ambos, garante que o processo judicial é "um conjunto de histórias contrapostas uma a outra. Sua lógica sequenciada permite ao juiz a compreensão do acontecimento dos fatos, da mesma forma que uma boa obra literária reporta o leitor ao entendimento linear de sua narração" (2006, p.60). Também se enquadra na segunda perspectiva a teoria do direito contado de François Ost, para quem o direito teria origem em narrações e não em fatos, devendo, portanto, ser contado e não simplesmente analisado (2005).

Pela terceira perspectiva, métodos de interpretação literária seriam aplicáveis a textos jurídicos. Sem dúvida, o que há de mais original e antipositivista no movimento. Talavera ilumina o assunto.

Rev. de Direito, Arte e Literatura | e-ISSN: 2525-9911 | Evento Virtual | v. 6 | n. 1 | p. 60-82 | Jan/Jun. 2020 
Em princípio, é importante sublinhar que o nexo de união entre a literatura e o direito que aos juristas anglo-saxões interessa é, basicamente, de natureza hermenêutica [enquanto brasileiros e europeus preferem o direito na literatura]. Em outras palavras, a originalidade dessa conexão radica em pressupor que o problema fundamental que estabelece o direito é hermenêutico, a saber: o processo de interpretação da lei que necessariamente devem fazer os juízes (e a interpretação da própria jurisprudência que devem fazer tanto juízes como juristas). De maneira que, como aponta Dworkin, podemos melhorar nosso conhecimento de direito se se compara a interpretação jurídica com a interpretação em outros campos do conhecimento; em particular, na literatura. O complexo problema da interpretação dos textos jurídicos buscou, pois, uma original via de solução tratando de estabelecer um paralelismo ou uma analogia com a hermenêutica literária, sempre desde o pressuposto de que toda norma jurídica, em definitivo, não é senão um enunciado linguístico (um relato) suscetível de ser submetido às regras interpretativas vigentes no terreno narrativo para determinar seu sentido. Ronald Dworkin e Richard Posner são quem, desde posições diversas, contribuíram em maior medida para materializar essa ponte hermenêutica (TALAVERA, 2006, p.57).

A verdade é que tais conflitos não se encontram pacificados sequer na Teoria da Literatura. Há quem pense, como Massaud Moisés, que Literatura é a expressão pela palavra escrita dos conteúdos da ficção ou imaginação, de modo que "somente se consideram literários os textos que se proponham específicos fins literários, vale dizer, o conto, a novela, o romance, a poesia e o teatro (este, apenas enquanto texto, não enquanto representação)" (2007, p.14). Nesse sentido, textos jurídicos não poderiam ser lidos como literários, muito menos com fins interpretativos. Posição diametralmente oposta é a de Antonio Candido, para quem Literatura são "todas as criações de toque poético, ficcional ou dramático em todos os níveis de uma sociedade, em todos os tipos de cultura, desde o que chamamos folclore, lenda, chiste, até as formas mais complexas e difíceis da produção escrita das grandes civilizações” (2004, p.16). Terry Eagleton aprofunda a questão.

Se é certo que muitas das obras estudadas como literatura nas instituições acadêmicas foram "construídas" para serem lidas como literatura, também é certo que muitas não o foram. Um segmento de texto pode começar sua existência como história ou filosofia, e depois passar a ser classificado como literatura; ou pode começar como literatura e passar a ser valorizado por seu significado arqueológico. Alguns textos nascem literários, outros atingem a condição de literários, e a outros tal condição é imposta. Sob esse aspecto, a produção do texto é muito mais importante do que o seu nascimento. O que importa pode não ser a origem do texto, mas o modo pelo qual as pessoas o consideram. Se elas decidirem que se trata de literatura, então, ao que parece, o texto será literatura, a despeito do que o seu autor tenha pensado (EAGLETON, 2006, p.13).

Um exemplo de texto que passou de documento histórico a literatura epistolar é a Carta de Pero Vaz de Caminha (GODOY, 2011). Nesse influxo, Vargas Llosa, segundo quem os romances, como os seres vivos, crescem, envelhecem e morrem. Os que sobrevivem mudam de pele ou de ser, pois "dizem às novas gerações coisas distintas das que disseram aos leitores quando apareceram e, às vezes, coisas que seu autor jamais pensou em comunicar através 
deles" (LLOSA, 2004, p.206). Contudo, novamente Massaud Moisés refuta a noção pela qual um texto será Literatura se as pessoas assim o considerarem e a despeito do que seu autor tenha pensado, in verbis: "que pessoas são essas, com tal poder? Os leitores? Os críticos, neles incluídos menos avisados, os idiossincráticos, os subjetivos, os servos de ideologias? Seriam uns e outros mais atilados do que o autor da obra em causa? Machado de Assis ignorava que Dom Casmurro é obra literária?” (2004, p.266-267).

De qualquer forma, cumpre reiterar que esse é um debate anglo-saxão. A maioria dos europeus, tal qual a maioria dos brasileiros, preocupa-se especialmente com o direito na literatura.

Se a cultura jurídica anglo-saxônica parece estar, decididamente, no rumo do interpretativismo, sendo que os estudos imperativistas se evidenciam em forte declínio, o mesmo não parece suceder, pelos menos não com a mesma intensidade, no mundo jurídico continental, onde os quadros mentais gerados pelo positivismo legalista modelam ainda grande parte da prática judicial e muito do labor doutrinal e acadêmico. Apesar de tudo isto, o facto é que, actualmente, também os debates mais ardentes da doutrina continental se travam não entre estas duas facções, interpretativista e imperativista, mas antes entre concepções várias da crítica interpretativista (AGUIAR E SILVA, 2001, p.80).

François Ost é o exemplo perfeito. Está entre os autores mais citados pelos brasileiros que pensam o Direito a partir da Literatura. Há duas explicações óbvias para isso. O professor belga é um entusiasta do estudo jurídico-literário e sempre privilegiou em sua obra o direito na literatura, assim como a maioria dos que publicam sobre o assunto no Brasil (MONTEIRO, 2016). Quanto ao interpretativismo, a expressão "guinada interpretativa", cunhada no final dos anos 1970 para registrar o que seria o advento de um novo paradigma das ciências sociais, vem sendo utilizada com frequência nos últimos vinte anos, tanto por autores anglo-saxões como por teóricos continentais, para aludir à evolução recente da Filosofia do Direito e qualificar globalmente o momento atual da cultura jurídica reflexiva (JUST, 2009). Lenio Luiz Streck, todavia, acredita que a guinada interpretativa não teve a devida recepção no cotidiano das práticas judiciárias e doutrinárias brasileiras (2009).

\subsection{O direito da literatura}

O direito da literatura corresponde às normas jurídicas que regulamentam a atividade literária, afigurando-se um campo de estudo notadamente pragmático. De acordo com Schwartz, compreende não só as relações jurídicas do exercício literário, como também as normas que orientam a criação e a difusão das obras (2006). Para Ost, o direito da literatura 
requer um interesse técnico e prático, ao invés de filosófico, como demandam as outras duas correntes (2005). Boa parte dos autores omite nas suas pesquisas o direito da literatura, law of literature, contentando-se em referi-lo sem maior exame ou detença. Já que o campo não traz nenhuma novidade, talvez seja apenas um tema correlato ao movimento, o qual, como quer Ian Ward, teria somente duas faces (2009). Talvez seja o caso de questionar até o caráter interdisciplinar. $\mathrm{O}$ direito da literatura não exige bagagem literária, porque é absolutamente dogmático. O próprio Posner investe em uma análise econômica quando examina a regulamentação da Literatura pelo Direito. Na quarta parte do seu Law and Literature, Posner discorre primeiro sobre a censura, depois sobre a difamação através de obra literária, para então abordar os direitos autorais. The Little Book of Plagiarism funciona como leitura complementar e ilumina os conceitos de autor, escritor, ghost writer, plágio, fair use, criptomnésia e paródia.

\section{O estado da arte no Brasil ${ }^{5}$}

A fim de traçar panorama histórico que permita avaliar o estado da arte dos estudos em Direito e Literatura no Brasil, vai-se recorrer - de novo com fins meramente didáticos e terminologia emprestada do movimento americano - a uma divisão em três fases: pais fundadores, movimento e empreendimento.

\subsection{Os pais fundadores}

No Brasil, os primeiros estudos sobre Direito e Literatura não sofreram qualquer influência estadunidense. Em 1946, Lemos Britto teve publicado seu livro O crime e os criminosos na literatura brasileira. Em 1959, Aloísio de Carvalho Filho reuniu cinco ensaios sob o título Machado de Assis e o problema penal. Lemos Britto afirmou não haver concebido uma obra de arte ou de crítica literária, tampouco um tratado de psicologia criminal, mas, sim, a fixação dos tipos e das formas criminais em todo o país. Aloísio de Carvalho Filho confessou ter-se inspirado em Mariano Ruiz Funes e suas Ideas penales de Anatole France para escrever os ensaios. Ao que parece, se houvessem recebido a devida

\footnotetext{
${ }^{5}$ Sobre o movimento nos Estados Unidos e na Europa, Direito e literatura: aproximações e perspectivas para se repensar o direito de André Karam Trindade e Roberta Magalhães Gubert.
} 
atenção, estes seriam os founding fathers do law in literature brasileiro, mas quase não se fala neles. A justificativa para a omissão talvez resida mesmo no desconhecimento. Daniel Nicory do Prado se pergunta "quantos outros Carvalhos Filho estarão escondidos pelas bibliotecas do país, omitidos pelo tempo e pela descontinuidade, inacessíveis aos novos e inquietos pesquisadores do 'Direito e Literatura"' (2007, p.148).

À inauguração do movimento, sobrevieram mais duas obras: em 1974, Machado de Assis: a pirâmide e o trapézio de Raymundo Faoro e, em 1998, Literatura e direito: uma outra leitura do mundo das leis de Eliane Botelho Junqueira. Entretanto, há uma resistência em se filiar tais autores ao Law and Literature Movement, pois ambos teriam propósitos menos jurídicos que políticos ou sociológicos.

Quando Raymundo Faoro se dispôs a enfrentar a obra de Machado de Assis em um
verdadeiro corpo-a-corpo com aquele universo de personagens e situações extraídas
do Brasil imperial, a sua obra-prima, Os donos do poder, já estava não só pronta,
pois fora editada em 1958, como acabava de ser inteiramente refundida, como se
adverte no prefácio à segunda edição, que é de 1975. Machado de Assis: a
pirâmide e o trapézio saiu em 1974. Por essa data depreende-se o quanto a intensa
leitura machadiana coincidiu com a retomada e o aprofundamento das suas teses
sobre a formação política brasileira (BOSI, 2004, p.355).

Quanto a Eliane Botelho Junqueira - não obstante tenha avaliado aspectos jurídicos em Machado de Assis, Lima Barreto, Graciliano Ramos e José Lins do Rego -, ela própria disse trabalhar "a partir do binômio literatura e ciências sociais" (1998, p.24).

Daí alguns pesquisadores atribuírem a Arnaldo Sampaio de Moraes Godoy o pioneirismo no Brasil, haja vista a sua dissertação de mestrado defendida em 2000 e publicada em 2002 sob o título Direito e literatura: anatomia de um desencanto: desilusão jurídica em Monteiro Lobato (PRADO, 2007). Em 2005, Luis Carlos Cancellier de Olivo analisou William Shakespeare juridicamente, comentando en passant as contribuições de Junqueira e Godoy n'O estudo do direito através da literatura (2005).

Não que a questão do pioneirismo seja substancial, porém, no seu Direito, literatura e cinema: inventário de possibilidades, Godoy admitiu desconhecer o movimento americano à época do mestrado (2011). Com efeito, Godoy só abordou o Law and Literature Movement em Direito e literatura: ensaio de síntese teórica, um trabalho de 2008.

Vera Karam de Chueiri testemunhou que, desde os anos 1980 na Universidade Federal de Santa Catarina, o professor argentino Luis Alberto Warat já trabalhava - se bem que de forma assistemática, sem dar nomes - com as interseções ou o entrelaçamento entre o Direito 
e manifestações estéticas como a Literatura (informação verbal) ${ }^{6}$. Lenio Luiz Streck foi mais categórico e afirmou que Luis Alberto Warat iniciou o Movimento Direito e Literatura no Brasil (informação verbal) ${ }^{7}$. No mesmo sentido, a oficina Warat e as origens do Direito e Literatura no Brasil, ministrada por Albano Marcos Bastos Pepe e Ângela Espíndola 8 .

\subsection{O movimento: publicações, grupos de pesquisa, eventos e cursos}

Ainda em 2005, criou-se o grupo de estudos Novum Organum? Temáticas entre Direito e Literatura, coordenado por Clarice Beatriz da Costa Söhngen na Pontifícia Universidade Católica do Rio Grande do Sul. As reuniões quinzenais ensejaram, em 2006, um primeiro seminário sobre Direito e Literatura, que se materializou, dois anos depois, no livro Encontros entre direito e literatura: pensar a arte. $\mathrm{O}$ segundo e o terceiro seminários do grupo tiveram lugar em 2007 e 2008, proporcionando novo livro, Encontros entre direito e literatura II: ética, estética e política, editado em 2010.

O ano de 2006 foi fundacional. Vicente de Paulo Barreto já trazia em seu Dicionário de filosofia do direito um verbete assinado por Vera Karam de Chueiri referente ao movimento americano. Mara Regina de Oliveira publicava Shakespeare e a filosofia do direito: um diálogo com a tragédia Júlio César. Vinha a lume, outrossim, A constituição, a literatura e o direito de Germano Schwartz, que ganharia tradução para o espanhol em 2011. Antes disso, em 2008, Germano Schwartz organizou com André Fernando dos Reis Trindade o livro de artigos Direito e literatura: o encontro entre Themis e Apolo e com Leonel Severo Rocha a Coleção Direito e Arte. O primeiro volume desta, Comunicação e direito: semiótica, literatura e norma, coube a Paulo Ferreira da Cunha; o segundo, Direito e literatura: ensaio de síntese teórica, a Arnaldo Sampaio de Moraes Godoy; o terceiro, Manual antitiranos: retórica, poder e literatura, a Maria Luísa Malato; e o quarto, A lista de Schindler: sobre abismos que o direito dificilmente alcança, publicado em 2009 como o terceiro, a Juan Antonio García Amado.

Despontava em 2006, ainda, a contribuição de Marcelo Campos Galuppo, que desde então orienta projetos sobre Direito e Literatura na Pontifícia Universidade Católica de Minas Gerais e, a partir de 2010, na Universidade Federal de Minas Gerais. À época, já ministravam

\footnotetext{
${ }^{6}$ I Simpósio de Direito e Literatura, Florianópolis, 2010.

${ }^{7} 144^{\circ}$ Programa Direito e Literatura. Os irmãos Karamázov, de Fiódor Dostoiévski.

${ }^{8}$ III Colóquio Internacional de Direito e Literatura, Passo Fundo, 2014.
} 
aulas relacionando Direito e Arte Cristiano Paixão na Universidade de Brasília; Mara Regina de Oliveira na Pontifícia Universidade Católica de São Paulo e na Universidade de São Paulo; e José Garcez Ghirardi na Fundação Getúlio Vargas. Ademais, surgia o grupo de pesquisa em Teoria do Direito, Democracia e Literatura da Universidade Federal do Paraná, o qual, liderado por Katya Kozicki e Vera Karam de Chueiri, desenvolveu os Estudos em direito, política e literatura: hermenêutica, justiça e democracia, publicados no mesmo ano. Principiavam, igualmente, os encontros e seminários fomentados pelo Instituto de Hermenêutica Jurídica do Rio Grande do Sul, que redundaram, em 2008, na edição de duas obras coletivas organizadas por André Karam Trindade, Roberta Magalhães Gubert e Alfredo Copetti Neto: Direito e literatura: reflexões teóricas e Direito e literatura: ensaios críticos. Os referidos autores organizariam um terceiro volume de artigos em 2010, intitulado Direito e literatura: discurso, imaginário e normatividade. O Instituto de Hermenêutica Jurídica do Rio Grande do Sul também promove desde 2008, com apoio da Universidade do Vale do Rio dos Sinos, um programa de televisão veiculado pela TV Justiça, apresentado por Lenio Luiz Streck e produzido por André Karam Trindade, o Direito e literatura: do fato à ficção. Em 2013, Streck e Trindade organizariam outro volume de artigos, Direito e literatura: da realidade da ficção à ficção da realidade, e seu programa televisivo receberia o Prêmio Açorianos de Literatura na categoria Destaques Literários.

Em 2007, foram publicados Antígona e o direito de Marcelo Alves e Direitos humanos e fundamentais: do discurso teórico à prática efetiva: um olhar por meio da literatura de Melina Girardi Fachin, assim como uma edição inteiramente dedicada à temática jurídico-literária da Revista da Faculdade Mineira de Direito. No mesmo ano, Daniel Nicory do Prado testemunhou que o Movimento Direito e Literatura era já um fenômeno nacional.

Pela primeira vez na curta mas fecunda história dos eventos científicos do Conselho Nacional de Pesquisa e Pós-Graduação em Direito (CONPEDI), foi organizado um Grupo de Trabalho sobre Direito e Literatura, durante o XVI Congresso Nacional da instituição, realizado em Belo Horizonte, entre os dias 15 e 17 de Novembro de 2007.

Nele, 12 (doze) trabalhos de professores, doutorandos, mestrandos e até de um graduando, de várias partes do país, foram apresentados. Tanto por sediar o evento como por possuir um grupo de pesquisa sobre o tema, a PUCMINAS apresentou 4 (quatro) trabalhos que, acompanhados de 1 (um) artigo da Universidade Federal de Minas Gerais (UFMG) e 1 (um) da Faculdade de Direito Milton Campos (FDMC), totalizaram seis apresentações de autores mineiros. A Universidade Federal da Bahia (UFBA) apresentou 2 (dois) trabalhos, sendo a instituição de ensino superior com a maior participação dentre as que não possuem nenhum grupo específico sobre o tema. A UFPR e o Centro Universitário de Maringá (CESUMAR) apresentaram 1 
(um) artigo cada, totalizando duas participações paranaenses. Por fim, a Universidade Estadual do Amazonas (UEA) e a Universidade Estadual Paulista (UNESP) fecharam o grupo, cada uma com 1 (um) trabalho (PRADO, 2007, p.151).

Daí por diante, todo encontro ou congresso do CONPEDI, que têm lugar semestral e intercaladamente, passou a contar com um grupo de trabalho sobre Direito e Literatura.

Também em 2007, começaram as atividades do grupo de pesquisa liderado por Luis Carlos Cancellier de Olivo na Universidade Federal de Santa Catarina, o Literato. Em 2009, passou a ser oferecida no Mestrado em Direito da UFSC a cadeira Seminário de Direito e Literatura. Em 2010, o Literato realizou seu primeiro simpósio, cujos anais foram organizados por Olivo no ano seguinte, inaugurando com três volumes a Coleção Direito e Literatura. O Literato foi criado em atenção ao trabalho de iniciação científica orientado por Olivo e desenvolvido pela então graduanda Ada Bogliolo Piancastelli de Siqueira. O quarto volume da coleção, que também saiu em 2011, contempla essa pesquisa e se intitula Notas sobre direito e literatura: o absurdo do direito em Albert Camus. O quinto volume, Por uma compreensão jurídica de Machado Assis, é mais uma obra de Olivo publicada em 2011. Tanto o sexto volume, Novas contribuições à pesquisa em direito e literatura, quanto o sétimo, Dostoiévski e a filosofia do direito: o discurso jurídico dos irmãos Karamázov, saíram em 2012, foram organizados por Olivo e concentram os textos elaborados pelos alunos da cadeira Seminário de Direito e Literatura em 2009 e 2010, respectivamente.

Em 2008, Cássio Schubsky e Miguel Matos trouxeram a lume Doutor Machado: o direito na vida e na obra de Machado de Assis. Já Carlyle Popp deu início ao grupo de pesquisa Direito Privado e Literatura no Centro Universitário Curitiba.

Em 2009, Judith Martins-Costa começou a reunir, ao ministrar a cadeira Fundamentos Culturais do Direito Privado na Pós-Graduação da Universidade Federal do Rio Grande do Sul, os seminários que originariam o livro Narração e normatividade: ensaios de direito e literatura, publicado em 2013.

Em 2010, saíram O problema da verdade: literatura e direito de Fernando Antônio Dusi Rocha e Direito constitucional intertextual: o teatro na cultura jurídica, organizado por Maria Garcia.

Em 2011, José Garcez Ghirardi publicou O mundo fora de prumo: transformação social e teoria política em Shakespeare. Marcelo Alves Dias de Souza lançou o primeiro volume de sua trilogia, Ensaios ingleses. Luís Carlos Martins Alves Jr. e Arnaldo Sampaio de 
Moraes Godoy passaram a liderar o grupo de pesquisa Direito e Literatura no Centro Universitário de Brasília e realizaram, em 2013, o I Seminário de Direito e Literatura do UniCEUB.

Em 2012, José Osterno Campos de Araújo publicou Direito penal na literatura: de Shakespeare, Machado e outros virtuoses e Marcelo Alves Dias de Souza, Retratos ingleses. Sebastião Trogo e Nuno Manuel Morgadinho dos Santos Coelho organizaram Direito, filosofia e arte: ensaios de fenomenologia do conflito. Campina Grande sediou o I Colóquio Direito, Cultura e Arte da Universidade Estadual da Paraíba. Aconteceu o I Encontro Internacional de Direitos Culturais da Universidade de Fortaleza, reeditado no ano seguinte com um grupo de trabalho sobre Direito e Arte. André Karam Trindade e Fausto Santos de Morais fundaram, junto à Escola de Direito da Faculdade Meridional, o Kathársis - Centro de Estudos em Direito e Literatura, realizando, no mesmo ano, o I Colóquio Internacional de Direito e Literatura.

O ano de 2013 só reafirmou o movimento. Márcio Barbosa Zerneri fundou o grupo de pesquisa Direito e Literatura: fundamentos para um diálogo interdisciplinar na Universidade Estadual de Londrina. Foram publicados Medida por medida: o direito em Shakespeare de José Roberto de Castro Neves, O Direito como garantia de pacificação e conciliação dos conflitos entre rivais na Itália Renascentista: uma análise da prática jurídica na tragédia Romeo and Juliet de William Shakespeare de Cristian Kiefer da Silva, Ideias penais na obra de Jorge Amado de Sérgio Habib, O antifetichismo institucional em Lima Barreto de Arnaldo Sampaio de Moraes Godoy e Códigos ingleses de Marcelo Alves Dias de Souza. Foram organizados Direito e literatura: por que devemos escrever narrativas? por Bernardo Nogueira e Ramon Mapa da Silva e Direito e literatura: estudos jurídicos baseados em obras literárias da segunda metade do século XIX por Andrés Botero e Lízia Medina. Tiveram lugar, em Teresina, o I Congresso Brasileiro de Direito e Literatura da Faculdade de Tecnologia de Teresina; em Salvador, duas edições do Colóquio Direito e Arte da Universidade Federal da Bahia; em Belo Horizonte, o XXVI Congresso Mundial de Filosofia do Direito e Filosofia Social da Internacionale Vereinigung für Rechts, com um working group e quatro workshops relacionando Direito e Arte; em São Paulo, a primeira edição do festival Pauliceia Literária da Associação dos Advogados de São Paulo, com debates ligados à ficção policial e ao Direito; em Fortaleza, o Seminário Literatura e Direito da Escola Superior da Magistratura do Estado do Ceará; em 
Passo Fundo, o II Colóquio Internacional de Direito e Literatura do Kathársis; em Recife, o IV Congresso da Associação Brasileira de Pesquisadores em Sociologia do Direito, com um grupo de trabalho sobre Direito e Arte; em Porto Alegre, as conferências sobre Direito e Literatura do Instituto Goethe, que Sonja Arnold e Michael Korfmann organizaram no livro Direito e literatura na virada do milênio; e, em Ilhabela, o Seminário da Feiticeira, promovido por Tercio Sampaio Ferraz Júnior, cujo tema foi Direito e Arte.

\subsection{O empreendimento: associação e revista especializada}

Parece lícito afirmar que o movimento está-se tornando empreendimento no Brasil.

Em 2014, são dignos de nota Kafka, alienação e deformidades da legalidade: exercício do controle social rumo à cidadania fiscal de Eurico Marcos Diniz de Santi, Direito e Literatura: interseções discursivas nas veredas da linguagem, organizado por Ângela Barbosa Franco e Maria Antonieta Rigueira Leal Gurgel, Direito e casos reais: cinema, literatura e música: uma nova forma de ver o direito civil, coordenado por Renata Domingues Balbino Munhoz Soares, uma edição inteiramente dedicada à temática jurídicoliterária da Revista do Instituto Humanitas Unisinos, o V Congresso da Associação Brasileira de Pesquisadores em Sociologia do Direito com mais um grupo de trabalho sobre Direito e Arte, o II Seminário Literatura e Direito da Escola Superior da Magistratura do Estado do Ceará, o III Colóquio Direito e Arte da UFBA, o I Seminário Direito e Arte da Universidade de Salvador, o III Colóquio Internacional de Direito e Literatura do Kathársis e o surgimento da primeira associação especialmente destinada a fomentar o Law and Literature no país, a Rede Brasileira Direito e Literatura.

Em 2015, foram publicados Shakespeare e o direito por Mara Regina de Oliveira e Arte e direito: o lugar da literatura na formação do jurista crítico-sensível por José Alexandre Ricciardi Sbizera. Foram organizados Os modelos de juiz: ensaios de direito e literatura por Lenio Luiz Streck e André Karam Trindade, Direito e literatura: e os múltiplos horizontes de compreensão pela arte por Nelson Camatta Moreira e Juliana Ferrari de Oliveira, Teoria poética do direito por Willis Santiago Guerra Filho e Paola Cantarini e Temas avançados de direito e arte por Rodolfo Pamplona Filho, Nelson Cerqueira e Claiz Maria Pereira Gunça dos Santos. Houve novas edições do Congresso da Associação Brasileira de Pesquisadores em Sociologia do Direito, do Colóquio 
Internacional de Direito e Literatura e do Pauliceia Literária. Além disso, o Congresso Nacional da FEPODI passou a contar com um grupo de trabalho sobre Direito e Arte e a RDL lançou a primeira revista do Brasil especializada em Direito e Literatura, a Anamorphosis.

\section{Conclusão}

À guisa de conclusão, um balanço. Não custa reforçar que, no Brasil, os estudos jurídico-literários antecederam o movimento americano e que nem todos os trabalhos sobre Direito e Literatura publicados após a década de 1970 tiveram influência estadunidense. No entanto, reconheça-se, foi necessário o movimento para que a temática ganhasse pertinência.

Salvo engano, o Brasil conta com mais de cinquenta livros filiáveis ao binômio Direito e Literatura - sem falar nas publicações em periódicos e nas monografias de graduação ou pós-graduação. Até mesmo faculdades tradicionais oferecem ou já ofereceram cadeiras e cursos de extensão relacionando as disciplinas. Em atividade, somam seis os grupos de pesquisa sobre Direito e Literatura registrados junto ao Conselho Nacional de Desenvolvimento Científico e Tecnológico. Nos eventos de Filosofia do Direito, os grupos de trabalho sobre Direito e Literatura não são mais novidade. Já se realizam, inclusive, vários eventos dedicados especificamente à temática jurídico-literária. Aparentemente, os pesquisadores sempre existiram, só faltava apoio institucional.

Nada obstante, os estudos pátrios ainda são incipientes. O Brasil ainda não tem um autor representativo ou icônico do movimento. Com efeito, por mais interdisciplinar que seja ou queira ser, o movimento abarca, a julgar pelos autores citados, bem menos literatos que juristas, até porque costuma propor o estudo do Direito a partir da Literatura e não o contrário. Nos volumes de artigos ou nos anais de eventos, raramente se encontram trabalhos de direito como literatura. Em verdade, as publicações brasileiras quase se circunscrevem ao direito na literatura, examinando menos escritores nacionais que estrangeiros. Inexistem, ademais, trabalhos sobre uma metodologia da pesquisa jurídico-literária.

\section{Referências $^{9}$}

\footnotetext{
${ }^{9}$ Deu-se preferência à bibliografia consultada em detrimento da citada ou recomendada.
} 
ADEODATO, João Maurício. Ética e retórica: para uma teoria da dogmática jurídica. São Paulo: Saraiva, 2006.

AGUIAR E SILVA, Joana. A prática judiciária entre direito e literatura. Coimbra: Almedina, 2001.

BINDER, Guyora; WEISBERG, Robert. Literary criticisms of law. New Jersey: Princeton University Press, 2000.

BOSI, Alfredo. Raymundo Faoro leitor de Machado de Assis. Estudos Avançados, vol.18, n.51, p.355-376, 2004.

BOTERO, Andrés. Derecho y literatura: un nuevo modelo para armar: instrucciones de uso. In: CALVO GONZÁLEZ, José. (Org.). Implicación derecho literatura: contribuciones a una teoría literaria del derecho. Granada: Comares, 2008, p.29-39.

CALVO GONZÁLEZ, José. Derecho y literatura: intersecciones instrumental, estructural y institucional. In: . (Org.). Implicación derecho literatura: contribuciones a una teoría literaria del derecho. Granada: Comares, 2008, p.3-28.

CANDIDO, Antonio. O direito à literatura e outros ensaios. Coimbra: Angelus Novus, 2004.

CARNEIRO, Maria Francisca. Direito, estética e arte de julgar. Porto Alegre: Núria Fabris, 2008.

Transdisciplinaridade na pesquisa jurídica. Revista Jurídica Cesumar - Mestrado, v.9, p.177-182, 2009.

DWORKIN, Ronald. Uma questão de princípio. Tradução de Luis Carlos Borges. São Paulo: Martins Fontes, 2000.

EAGLETON, Terry. Teoria da literatura: uma introdução. Tradução de Waltensir Dutra. São Paulo: Martins Fontes, 2006.

FERRAZ JUNIOR, Tercio Sampaio. Estudos de filosofia do direito: reflexões sobre o poder, a liberdade, a justiça e o direito. São Paulo: Atlas, 2009.

O direito, entre o futuro e o passado. São Paulo: Noeses, 2014.

FERREIRA DA CUNHA, Paulo. Comunicação e direito: semiótica, literatura e norma. Porto Alegre: Livraria do Advogado, 2008a.

. Direito e literatura: introdução a um diálogo. In: TRINDADE, André Fernando dos

Reis; SCHWARTZ, Germano. (Org.). Direito e literatura: o encontro entre Themis e Apolo. Curitiba: Juruá, 2008b, p.7-13.

GODOY, Arnaldo Sampaio de Moraes. Direito, literatura e cinema: inventário de possibilidades. São Paulo: Quartier Latin, 2011.

JAPIASSU, Hilton. Interdisciplinariedade e patologia do saber. Rio de Janeiro: Imago, 1976.

JUNQUEIRA, Eliane Botelho. Literatura e direito: uma outra leitura do mundo das leis. Rio de Janeiro: Letra Capital, 1998.

JUST, Gustavo. Guinada interpretativa. In: BARRETO, Vicente de Paulo. (Org.). Dicionário de filosofia do direito. São Leopoldo: Unisinos; Rio de Janeiro: Renovar, 2009, p.394-399.

KOZICKI, Katya. Apresentação. In: ; CHUEIRI, Vera Karam de. (Org.). Estudos em direito, política e literatura: hermenêutica, justiça e democracia. Curitiba: Juruá, 2006, p.5-12.

MALAURIE, Philippe. Droit et littérature: une anthologie. Paris: Cujas, 1997.

MARTINS-COSTA, Judith. Direito e literatura, linguagem. In: ADEODATO, João Maurício; BITTAR, Eduardo Carlos Bianca. (Org.). Filosofia e teoria geral do direito: homenagem a Tercio Sampaio Ferraz Junior. São Paulo: Quatier Latin, 2011, p.703-718. 
Nota da coordenadora: entre prestação de contas e introdução. In: (Org.).

Narração e normatividade: ensaios de direito e literatura. Rio de Janeiro: GZ, 2013. MOISÉS, Massaud. Dicionário de termos literários. São Paulo: Cultrix, 2004.

A análise literária. São Paulo: Cultrix, 2007.

MONTEIRO, Eduardo Aleixo. Direito e literatura: a crítica de Richard Posner ao law and literature movement. Trabalho de Conclusão de Curso (Bacharelado em Direito) - Faculdade de Direito da Universidade Federal de Pernambuco, Recife, 2012.

Direito e literatura: a metodologia da pesquisa jurídico-literária de François Ost aplicada a'O juiz de paz da roça de Martins Pena. Dissertação (Mestrado em Filosofia e Teoria Geral do Direito) - Faculdade de Direito da Universidade de São Paulo, São Paulo, 2016.

MORAWETZ, Thomas. Law and literature. In: PATTERSON, Dennis. (Org.). A companion to philosophy of legal and legal theory. Malden: Blackwell, 1996, p.450-461.

NUSSBAUM, Martha. Poetic justice: the literary imagination and public life. Boston: Beacon Press, 1995.

OLIVO, Luis Carlos Cancellier de. O estudo do direito através da literatura. Tubarão: Editorial Studium, 2005.

OST, François. Contar a lei: as fontes do imaginário jurídico. Tradução de Paulo Neves. São Leopoldo: Unisinos, 2005.

PÉREZ, Carlos. Derecho y Literatura. Isonomía, n.24, p.135-153, 2006.

PESSOA, Fernando. Textos de crítica e de intervenção. Lisboa: Ática, 1980.

POSNER, Richard. Cardozo: a study in reputation. Chicago: The University of Chicago Press, 1990.

Law and literature: third edition. Cambridge: Harvard University Press, 2009.

SALAMA, Bruno Meyerhof. O que é direito e economia? In: TIMM, Luciano Benetti. (Org.). Direito e economia. Porto Alegre: Livraria do Advogado, 2008, p.49-61.

SCHWARTZ, Germano. A constituição, a literatura e o direito. Porto Alegre: Livraria do Advogado, 2006.

SELIGMANN-SILVA, Márcio. Apresentação. In: OLIVO, Luis Carlos. Dostoiévski e a filosofia do direito: o discurso jurídico dos irmãos Karamázov. Florianópolis: Editora da UFSC: Fundação Boiteux, 2012.

SÖHNGEN, Clarice Beatriz da Costa. Introdução. In:

; PANDOLFO, Alexandre

Costi. (Org.). Encontros entre direito e literatura: pensar a arte. Porto Alegre: EDIPUCRS, 2008, p.13-15.

STRECK, Lenio Luiz. Hermenêutica jurídica e(m) crise: uma exploração hermenêutica da construção do direito. Porto Alegre: Livraria do Advogado, 2009.

TALAVERA, Pedro. Derecho y literatura. Granada: Comares, 2006.

TRINDADE, André Karam; GUBERT, Roberta Magalhães. Direito e literatura: aproximações e perspectivas para se repensar o direito. In: ___ _ _ _ COPETTI

NETO, Alfredo. (Org.). Direito e literatura: reflexões teóricas. Porto Alegre: Livraria do Advogado, 2008, p.11-66.

VARGAS LLOSA, Mario. A verdade das mentiras. Tradução de Cordelia Magalhães. São Paulo: Arx, 2004.

WARAT, Luis Alberto. Territórios desconhecidos: a procura surrealista pelos lugares do abandono do sentido e da reconstrução da subjetividade. Florianópolis: Fundação Boiteux, 2004.

WARD, Ian. Law and literature: possibilities and perspectives. New York: Cambridge University Press, 2009.

Rev. de Direito, Arte e Literatura | e-ISSN: 2525-9911 | Evento Virtual | v. 6 | n. 1 | p. 60-82 | 
WEISBERG, Richard. Law in and as literature: self-generated meaning in the "procedural novel". In: KOELB, Clayton; NOAKES, Susan. The comparative perspective on literature: approaches to theory and practice. New York: Cornell University Press, 1988, p.224-232.

. Wigmore, and the law and literature movement. Cardozo Legal Studies Research Paper, n.177, 2006. Disponível em: <http://ssrn.com/abstract=951700>. Acesso em: 10 jan. 2012.

WHITE, James Boyd. From expectation to experience: essays on law and legal education. Ann Arbor: University of Michigan Press, 2000.

YOSHINO, Kenji. The city and the poet. 114 Yale Law Journal, p.1835-1896, 2005. 